\title{
Oleos essenciais
}

\section{de espécies do gênero Calyptranthes}

R. G. CAMPOS CORREA(1), M. LEÃO DA SILVA( $\left.{ }^{1}\right), J$, G. SOARES MAIA(1), O, R. GOTTLIEB $\left({ }^{2}\right)$, J. CORREA MOURÅO $\left({ }^{2}\right)$, M. C. MARX $\left({ }^{2}\right)$, A. ALPANDE DE MORAES $\left({ }^{2}\right), M$. KOKETSU $\left({ }^{3}\right)$, L. LANNES MOURA $\left({ }^{3}\right)$, e M. TAVEIRA MAGALHÃES( $\left.{ }^{4}\right)$.

\section{SINOPSE}

Na Amazônia se encontram algumas espécies de Calyptranthes (Myrtaceae). A comparação do b́leo essencial de suas folhas varia de espécie para espécie. Assim é que o óleo destilado de C. sprucean丸 Berg (rendimento de $1,7 \%$ ) contém os terpenos $\propto$ - pineno $(5,8 \%), \beta$ - pineno $(8,1 \%)$, limoneno $(54,6 \%)$, um alcool monoterpênico $(1,2 \%)$, neral $(2,0 \%)$, geranial $(3,2 \%)$ e perilaldeido $(25,0 \%)$; enquanto o óleo destilado de uma espécie de Calyptranthes não identificada (rendimento $2,2 \%$ ), contém metilchavicol de alilbenzeno $(98,7 \%)$.

Calyptranthes spruceana é uma espécie arbórea que pode atingir até três metros de altura, encontrada na Amazônia (Manaus), em regiōes inundáveis à beira de rios. O forte cheiro de laranja, que exala de suas folhas, a que deve a designação "laranjinha", acha-se modificado por um odor característico de cuminho, razão porque é também denominada, por alguns, "cuminirana".

Por arraste a vapor e coobação das águas condensadas, obtivemos das folhas um óleo essencial com rendimento de $1,7 \%$. Análise desse óleo por cromatografia gás-liquido (Cromatógrafo modelo CG-12 da Instrumentos CG, Sẽo Paulo, operando com coluna de aço inoxidável de $2 \mathrm{~m}$ de comprimento e $3 / 16$ " de diâmetro, carregada com $10 \%$ de Carbowax $20 \mathrm{M}$ sobre Chromosorb W, temperatura de 70 a $180^{\circ}$ ) evidenciou a presença de sete constituintes. Análise em cromatógrafo gás-líquido acoplado com espectrômetro de massa (conjunto Perkin-Elmer, operando com coluna de aço inoxidável de $2 \mathrm{~m}$

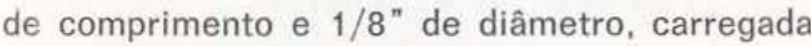
com $5 \%$ de Metilsilicona SE-30 sobre Chromo- sorb W, temperatura de 65 a $120^{\circ}$ ) identificou a natureza monoterpênica de todos esses constituintes. A separação dos mesmos foi realizada em cromatógrafo gás-líquido preparativo (Aparelho Aerograph Autoprep modêlo 705 da Varian, operando com coluna de alumínio de $3,3 \mathrm{~m}$ de comprimento e $3 / 8^{\prime \prime}$ de diâmetro, carregada com $30 \%$ de Metilsilicona SE-30 sobre Chromosorb $W$, temperatura de 80 a $200^{\circ}$ ). A identificação dos constituintes isolados processou-se pela aplicação das espectrometrias no infravermelho, de ressonância magnética nuclear e de massa.

Conforme se indica na Tabela, é o limoneno o principal constituinte do óleo essencial $(54.6 \%)$.

Um alcool monoterpênico, para o qual se propõe, tentativamente, a estrutra de 1-hidroxi-p-ment-8-eno, foi caracterizado pela interpretação dos seguintes resultados: $\mathrm{O}$ espectro de massa apresentou pico molecular em 154 u.m a., pico base em m/e 41 e outros picos em m/e 43 . 121 e 136. O fragmento em $\mathrm{m} / \mathrm{e} 41$ identifica o grupo isopropenila e o fragmento em m/e 136 ( $M-18$ ) identifica a natureza alcoólica do constituinte. O espectro de ressonância magnética nuclear apresentou uma banda múltipla em 5.35 6 que caracteriza uma ligação dupla terminal; uma banda com desdobramento secundário em 8.32̌ $z$ que caracteriza um grupo metila vinilico; uma banda simples em 8,8 6 que caracteriza uma metila ligada a carbono carbinólico quaternário e uma banda larga em 6,48 6 que pode corresponder ao proton hidroxílico. O espectro no infravermelho apresentou bandas que caracterizam um grupo hidroxila e uma ligação dupla

\footnotetext{
(1) - Instituto Nacional de Pesquisas da Amazônia, Conselho Nacional de Pesquisas, Manaus

(2) - Universidade Federal Rural do Rio de Janeiro.

(3) - Insttiuto de Tecnologia de Oleos, Ministério da Agricultura, Rio de Janeiro.

(4) - Instituto de Tecnologia Alimentar, Ministério da Agricultura, Rio de Janeiro.
} 
di-substituída terminal. Devido a massa molecular(154), o composto deve ter duas insuficiências de hidrogênio, provavelmente uma ligação dupla e um anel.

O aldeído perílico $(25 \%)$ que é o responsável pelo cheiro de cuminho, foi identificado pela interpretação dos seguintes resultados: $\mathrm{O}$ espectro de massa apresentou pico molecular em 150 u.m.a., pico base em m/e 68, correspondente a um fragmento oriundo por uma reaçăo retro Diels-Alder do anel ciclohexênico, e um pico em $\mathrm{m} / \mathrm{e} 41$, característico do grupo isopropenila. Os espectros no infravermelho e de ressonância magnética nuclear apresentaram bandas características das funções aldeído, carbonila $\alpha, \beta$-insaturada, dupla ligação tri-substituída, dupla ligação di-substituída terminal e grupamento metila vinílico.

Em contraposição a este óleo de natureza monoterpênica, obtivemos das folhas de outra espécie do gênero Calyptranthes, um óleo es- sencial de natureza aromática, contendo como constituinte principal o metilchavicol $(98,7 \%)$. A identificação foi feita por cromatografia gáslíquido e espectrometria de ressonância magné tica nuclear. Uma pequena quantidade de terpenos $(1,3 \%)$ acompanha o metilchavicol.

A planta estudada não foi localizada no seu habitat, a Amazônia, e sim no Jardim Botânico ao Rio de Janeiro, onde está registrada sob n. ${ }^{\circ}$ 2797 e a designação de "pau de erva doce". Trata-se de uma árvore de porte médio, original do rio Trombetas, Estado do Pará. O Dr. J. R Mattos classificou o vegetal como uma mirtácea do gênero Calyptranthes. Ausência prolongada de florescimento e frutificação impediram. até o momento, a identificação da espécie.

\section{Agradecimentos}

Agradecimentos são devidos ao Conselho Nacional de Pesquisas por suporte financeiro eo presente trabalho.

\section{COMPOSIÇÃO PERCENTUAL DE ÓLEOS ESSENCIAIS DE FOLHAS DE ESPÉCIES DE CALYPTRANTHES}

SEPARAC̣ÃO IDENTIFICAC̣ÃO

\begin{tabular}{|c|c|c|c|}
\hline $\begin{array}{l}\text { C. spruceana Berg } \\
\alpha \text {-pineno } \\
\beta \text {-pineno } \\
\text { Limoneno } \\
\text { Alcool monoterpênico } \\
\text { Neral } \\
\text { Geranial } \\
\text { Aldeído Perílico }\end{array}$ & $\begin{array}{r}1,7 \% \\
5,8 \\
8,1 \\
54,6 \\
1,2 \\
2,0 \\
3,2 \\
25,0\end{array}$ & $\begin{array}{l}\text { CGL } \\
\text { CGL } \\
\text { CGL } \\
\text { CGL } \\
\text { CGL } \\
\text { CGL }\end{array}$ & $\begin{array}{l}\text { IV, RMN, EM } \\
\text { IV. RMN, EM } \\
\text { IV. RMN, EM } \\
\text { IV, RMN, EM (M 154) } \\
\text { IV, RMN, EM } \\
\text { IV, RMN, EM }\end{array}$ \\
\hline Calyptranthes sp. & $2,2 \%$ & & \\
\hline $\begin{array}{l}\text { Terpenos } \\
\text { Metilchavicol }\end{array}$ & $\begin{array}{r}1,3 \\
98,7\end{array}$ & & $\begin{array}{l}\text { CGL } \\
\text { CGL, RMN }\end{array}$ \\
\hline
\end{tabular}

\section{SUMMARY}

Several arboreous Calyptranthes (Myrtaceae) species occur in Amazonia. The composition of the essential oil of their leaves varies widely from species to species. Thus, the oil distilled from C. sprucema Berg (Yield 1,7\%) contains the terpenes $\propto$ - pinene
$(5,8 \%), \beta$ - pinene $(8,1 \%)$, limonene $(54,6 \%)$, a monoterpenic alcohol $(1,2 \%)$, neral $(2,0 \%)$, geranial $(3,2 \%)$ and perillaldehyde $(25,0 \%)$; while the oil distilled from an unidentified Calyptranthes species (yield $2,2 \%$ ) contains the allylbenzene methylchavicol $(98,7 \%)$ 